\title{
EFFECT OF ADDITIVES ON STATIC SETTLED CONCENTRATION, pH AND VISCOSITY OF BOTTOM ASH-WATER SUSPENSION
}

\author{
KAUSHAL Kumar¹, SATISH Kumar², AJAY Kumar' \\ ${ }^{I}$ Department of Mechanical Engineering, K.R. Mangalam University Gurugram-122103, Haryana, \\ INDIA, e-mail: ghanghaskaushal@gmail.com, akrathee86@gmail.com \\ ${ }^{2}$ Department of Mechanical Engineering, National Institute of Technology, Jamshedpur -831014, \\ Jharkhand, INDIA, e-mail: satish.kumar@thapar.edu
}

\begin{abstract}
In the present work, static settled concentration, $\mathrm{pH}$ and viscosity of bottom ash is studied with addition of additive. Sodium sulfate is used as an additive with proportion of $0.2,0.4$ and $0.6 \%$ (by weight). The solid concentration of bottom ash suspension varied from 20 to 50\% (by weight). Remarkable improvement has been observed in static settled concentration, $\mathrm{pH}$ and viscosity with addition of sodium sulfate with proportion of $0.4 \%$. Reduction in relative viscosity is highly pronounced at higher solid concentration. Similar observation has been reported for static settled concentration and $\mathrm{pH}$ of slurry suspension. Addition of additive in bottom ash suspension improves the rheological characteristics which can be beneficial for conveying bottom ash slurry suspension at higher concentration.
\end{abstract}

KEYWORDS: Bottom ash, Rheology, Relative viscosity, Static settled concentration, pH.

\section{Introduction}

In thermal power plants, large amount of ash is producing through the combustion of coal [1]. Coarser particle of coal ash collected under the boiler furnace, termed as bottom ash. Indian thermal power plants generate approximately 1,200,000MW electricity and produce 60 million tons of bottom ash per year [2]. Bottom ash is transporting through hydraulic pipeline from the plant to disposed area ponds. Presently bottom ash is being transported as lean mixture through pump and pipelines. During the transportation of bottom ash large amount of water and pumping power is required [2-5]. To overcome this requirement, suitable design of slurry transportation system is needed. The basic parameters of any slurry transportation system are hydraulic parameters, which depends on rheological and physical properties of solid liquid suspension like particle size distribution, specific gravity, static settled concentration and relative viscosity etc.

Various researchers have examined the rheological characteristics for ash slurry suspensions [6 - 12]. Researchers used different mathematical equations to study the parametric relations between different linear and non-linear characteristics [13, 14]. Researchers also reported that addition of some additive in coal ash slurry, able to changes the rheological characteristics drastically [15 - 18]. Different researchers studied different parametric effluence, Even though very limited work has been reported on the effect of additive on static settled concentration and relative viscosity of bottom ash suspension at higher solid concentrations. The present study deals with the effect of additive on static settled concentration, $\mathrm{pH}$ and viscosity of bottom ash suspension. Sodium sulfate was used as an additive in proportion of $0.2,0.4$ and $0.6 \%$ (by weight). 


\section{Methods and Materials}

Text In order to characterization, bottom ash sample is collected under the hopper of from the Rajiv Gandhi thermal power plant, Hisar, Haryana, India. A number of bench scale tests are conducted to analyse the physico-chemical characteristics of bottom ash sample. Energydispersive X-ray spectroscopy (JEOL, 6510LV model) is used to analyse the chemical composition of bottom ash sample, as shown in Fig. 1. It is found that the sample of bottom ash predominantly enriched with $\mathrm{Al}_{2} \mathrm{O}_{3}$ and $\mathrm{SiO}_{2}$ as compared to other elements. The presence of more $\mathrm{Al} / \mathrm{Si}$ indicating towards causing more drag effects on the flow behavior of the slurry suspension [18 - 20]. Mechanical sieve shaker with standard sieves is used to determine the particle size distribution of bottom ash sample. It is found that about $62.50 \%$ particles are coarser than $150 \mu \mathrm{m}$ while only $7.40 \%$ particles are finer than $53 \mu \mathrm{m}$. The particle size distribution of bottom ash sample is represents in Fig. 2. The Specific gravity of bottom ash sample is measured as 1.94 by using pycnometer method. The static settled concentration value is measured by gravitational method with initial solid concentration i.e. $20 \%$ (by weight). During settling process of slurry suspension at fixed interval of time, slurry level is recorded. The final static settled concentration of bottom ash slurry suspension has been recorded as $52.15 \%$ (by weight). Digital electrode $\mathrm{pH}$ meter is used for measuring the $\mathrm{pH}$ value of slurry suspension. For bottom ash concentration 20 to $50 \%$ (by weight) the $\mathrm{pH}$ values lie in the range of 7.70 to 7.40 respectively. Results of $\mathrm{pH}$ value are indicating towards the non-reactive nature of bottom ash slurry suspension.

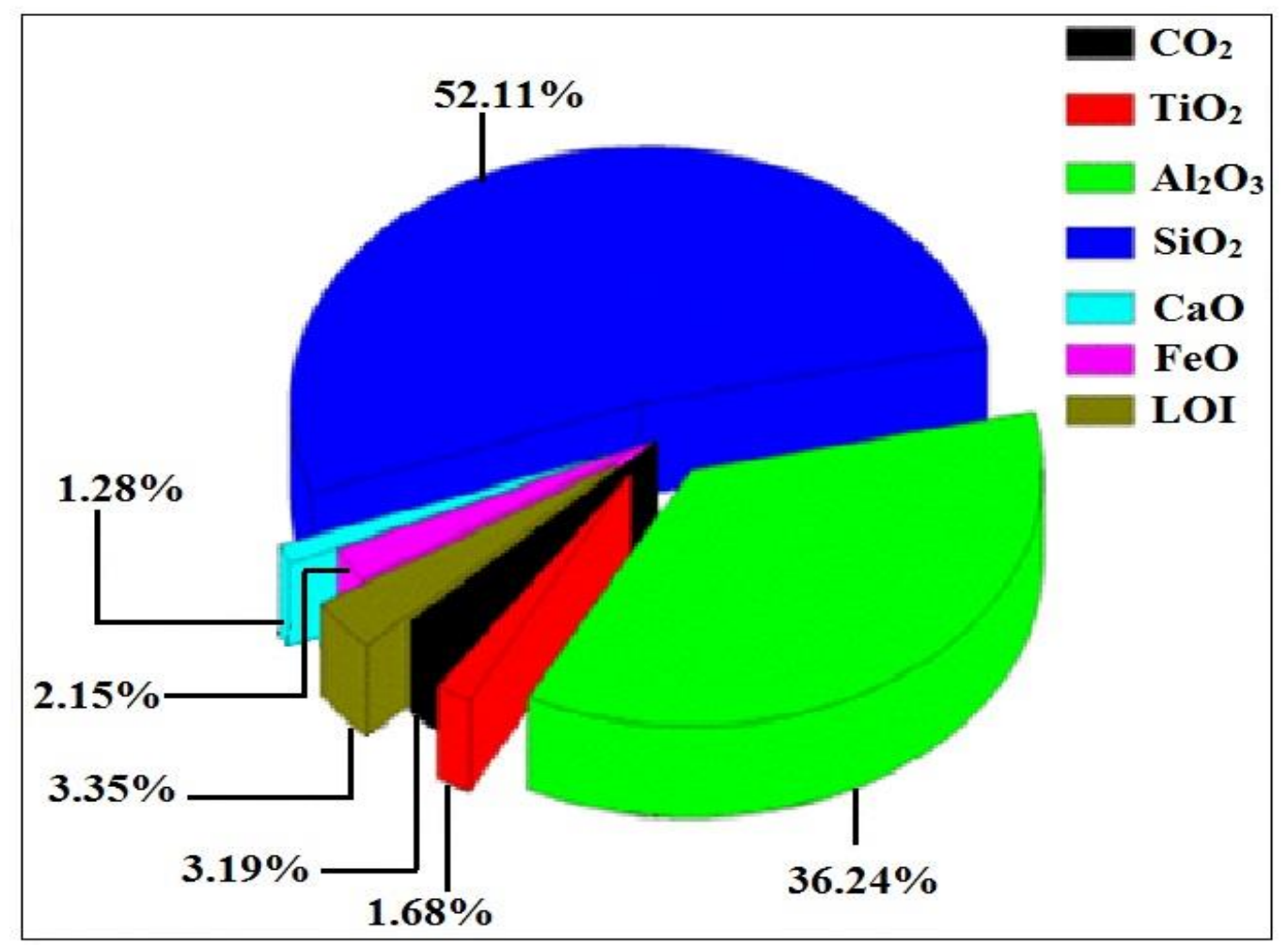

Fig. 1 Chemical composition of bottom ash sample 


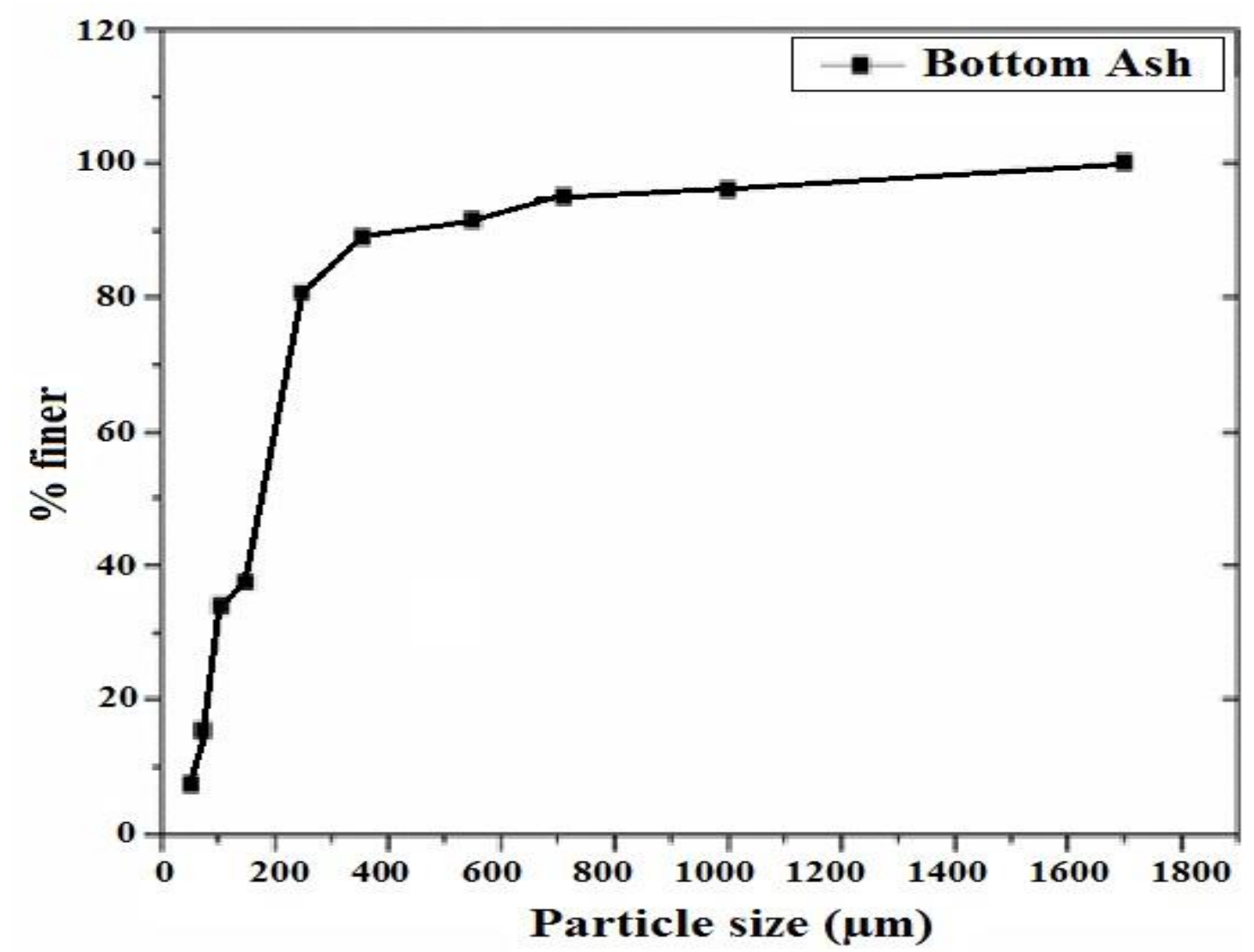

Fig. 2 Particle size distribution of bottom ash sample

\section{Experimental Procedure}

The rheological experiments are conducted with the help of ISO: certified rheometer (Manufactured by: Rheolab Q-C, APC Ltd. Germany) as shown in Fig 3. This rheometer works on the Searle principle. Rotary cylinder (bob) inside the stationary cup is working with the help of motor. The bob have fixed gyratory speed and generate sufficient torque to revolve the measuring bob. This adequate torque has to overwhelm viscous forces of the tested matter and measure its viscosity. Viscosity of slurry has been measured with the help of concentric cylinder measurement method (based on DIN EN ISO 3219 and DIN 53019). Detailed specification of the Rheometer is given in Table 1.

Table 1- Specification of the rheometer (Rheolab QC)

\begin{tabular}{|l|l|l|}
\hline S. No. & Component & Specifications \\
\hline 1 & Motor type & Synchronous EC motor \\
\hline 2 & Speed range & 0.01 to $1200\left(\mathrm{~min}^{-1}\right)$ \\
\hline 3 & Shear stress range & 0.5 to $3 \times 10^{7}(\mathrm{mPa})$ \\
\hline 4 & Shear rate range & 0.01 to $4000\left(\mathrm{~s}^{-1}\right)$ \\
\hline 5 & Viscosity range & 0.1 to $10^{9}(\mathrm{mPas})$ \\
\hline 6 & Temperature range & -20 to $180\left({ }^{\circ} \mathrm{C}\right)$ \\
\hline 7 & Angular resolution & $2 \mu \mathrm{red}$ \\
\hline
\end{tabular}

Rheological tests are conducted under the variation of shear rate value in range of 50-150 $\mathrm{s}^{-1}$ at solid concentration of 20 to $50 \%$ (by weight). Similar procedure is also repeated for bottom ah slurry suspension with addition of additive. Sodium sulphate is used as an additive with proportion $0.2,0.4$ and 0.6 (\% by weight) in all solid concentrations of bottom ash slurries. Experiments are repeated to ensure the precision of measured data. 


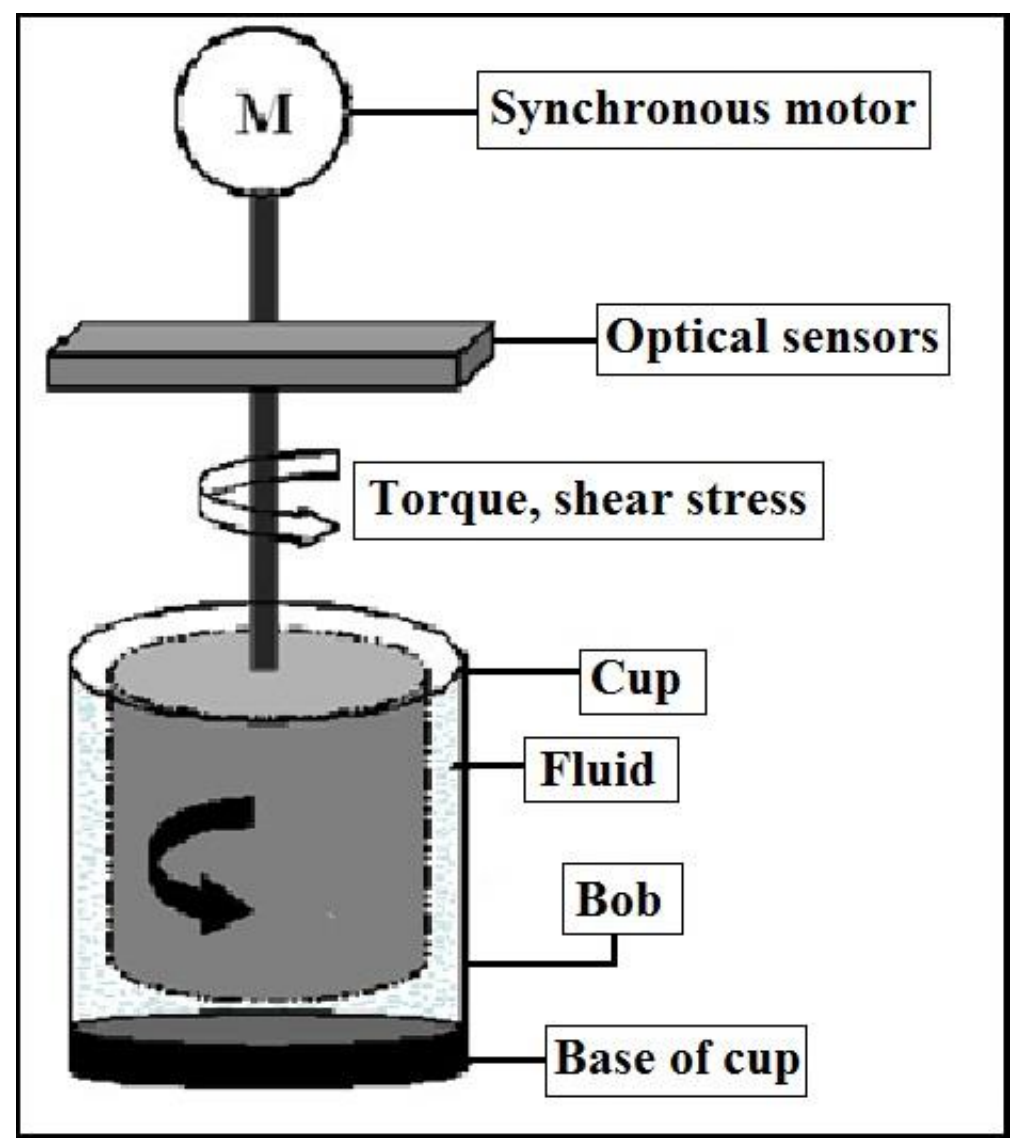

Fig. 3 Schematic of rheometer

The rheology of bottom ash is determined by calculation of shear stress at a particular value of shear rate. Initially the rheometer is calibrated by using tap water for its reliability. A locking device enables the fixing of rotating bob and cup which is done prior from laboratory testing. For rheological tests, a $100 \mathrm{ml}$ bottom ash slurry sample is prepared through proper mixing of water and ash with the help of glass rod. The slurry suspension is poured into cup (cylinder) till the specified mark after weighing on electronic type pan balance with least count of $\pm 0.001 \mathrm{mg}$. The suspension is poured out in the cup of rheometer at level of specified mark. Bottom ash slurry exists in the gap between two cylinders. Shearing action of slurry suspension is begins with the rotation of bob under the action of drag force applied by motor.

\section{$4 \quad$ Results and Discussion}

The rheology of bottom ash is determined by calculation of shear stress at a particular value of shear rate. The measure of shear stress vs. shear rate represents the rheological behavior of any liquid or solid-liquid. The rheological behavior of bottom ash suspensions are evaluated for solid concentration of 20-50 (\% by weight). Fig. 4 shows shear stress vs. shear rate curves for bottom ash slurry predicted at different solid concentrations. Results represents non-Newtonian nature of slurry suspension follows Bingham fluid behavior as shown in equation 1:

$$
\tau=\tau_{y}+\eta \frac{d u}{d y}
$$


where, $\tau=$ shear stress $(\mathrm{Pa}), \tau_{y}=$ Bingham yield stress $(\mathrm{Pa})$, and $\eta=$ Coefficient of rigidity or Bingham viscosity. Coefficient of rigidity is used in case of Bingham fluid for measuring the relative viscosity. All data is fitted in straight line equation to find viscosity for each slurry suspension sample. The bottom ash slurry suspension show Newtonian behaviour up to $40 \%$ solid concentration (by weight) beyond depicts non-Newtonian flow characteristics. The value of shear stress at shear rate of $50 \mathrm{~s}^{-1}$ is observed as $0.075,0.110,0.150$ and 0.290 pascal whereas at shear rate of $200 \mathrm{~s}^{-1}$, observed as $0.296,0.445,0.595$ and 1.211 pascal for solid concentration of 20,30, 40 and 50\% (by weight) respectively.

The shear stress value increases about 3.87 and 4.1 times with increase in value of $\mathrm{C}_{\mathrm{w}}$ from 20 to $50 \%$ at shear rate of 50 and $200 \mathrm{~s}^{-1}$ respectively. Similar observations are also made by researchers [9-13].

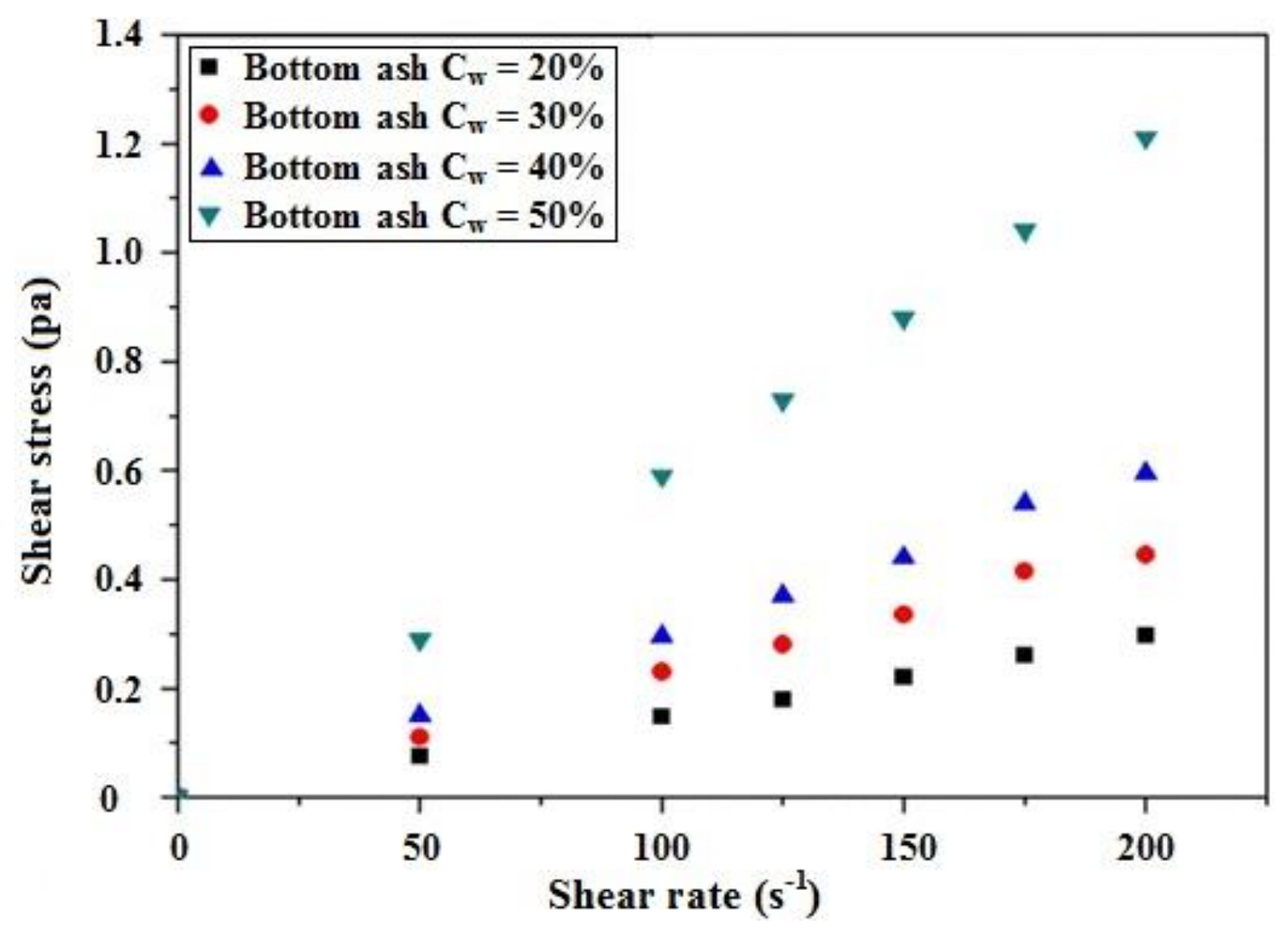

Fig. 4 Shear stress vs. shear rate curves

\section{Effect of additive on relative viscosity of bottom ash suspension}

Experimentation has been carried out to study the effect of additive on relative viscosity of bottom ash slurry with varying solid concentration. The relative viscosity of bottom ash suspension is studied at solid concentration of 20-50 (\% by weight) with and without addition of additive. The sodium sulfate is used as an additive in small proportion by weight $(0.2-0.6 \%$ of total solids). The data measured at room temperature is shown in Fig 5. From experimental data it is concluded that relative viscosity of bottom ash suspension is reduced with increase in proportion of additives from 0.2 to $0.6 \%$ at fix value of solid concentration.

Moreover, the presence of additive in suspension promotes particle dispersion and permits the reduction of surface tension as well as interparticulate forces of particles which resulting in reduction of Bingham viscosity. Similar observations are also made by researchers [19 21]. At solid concentration of $20 \%$ (by weight), relative viscosity of bottom ash suspension is 
reduced in the percentage of $4.36,8.77$ and $4.99 \%$ with the addition of sodium sulfate in the proportion of $0.2,0.4$ and $0.6 \%$ respectively. Similar trend of decreasing relative viscosity is also observed for additive of sodium sulfate at solid concentration of $50 \%$ (by weight). Relative viscosity of bottom ash suspension is reduced in the percentage of 10.92, 16.66 and $12.88 \%$ with the addition of sodium sulfate in the proportion of $0.2,0.4$ and $0.6 \%$ respectively. From the experimental data, it is clearly noticed that reduction in relative viscosity is more pronounced at higher solid concentration. Moreover, the higher reduction in relative viscosity is noticed with addition of sodium sulfate in proportion of $0.4 \%$ (by weight) as compared to 0.2 and $0.6 \%$ (by weight).

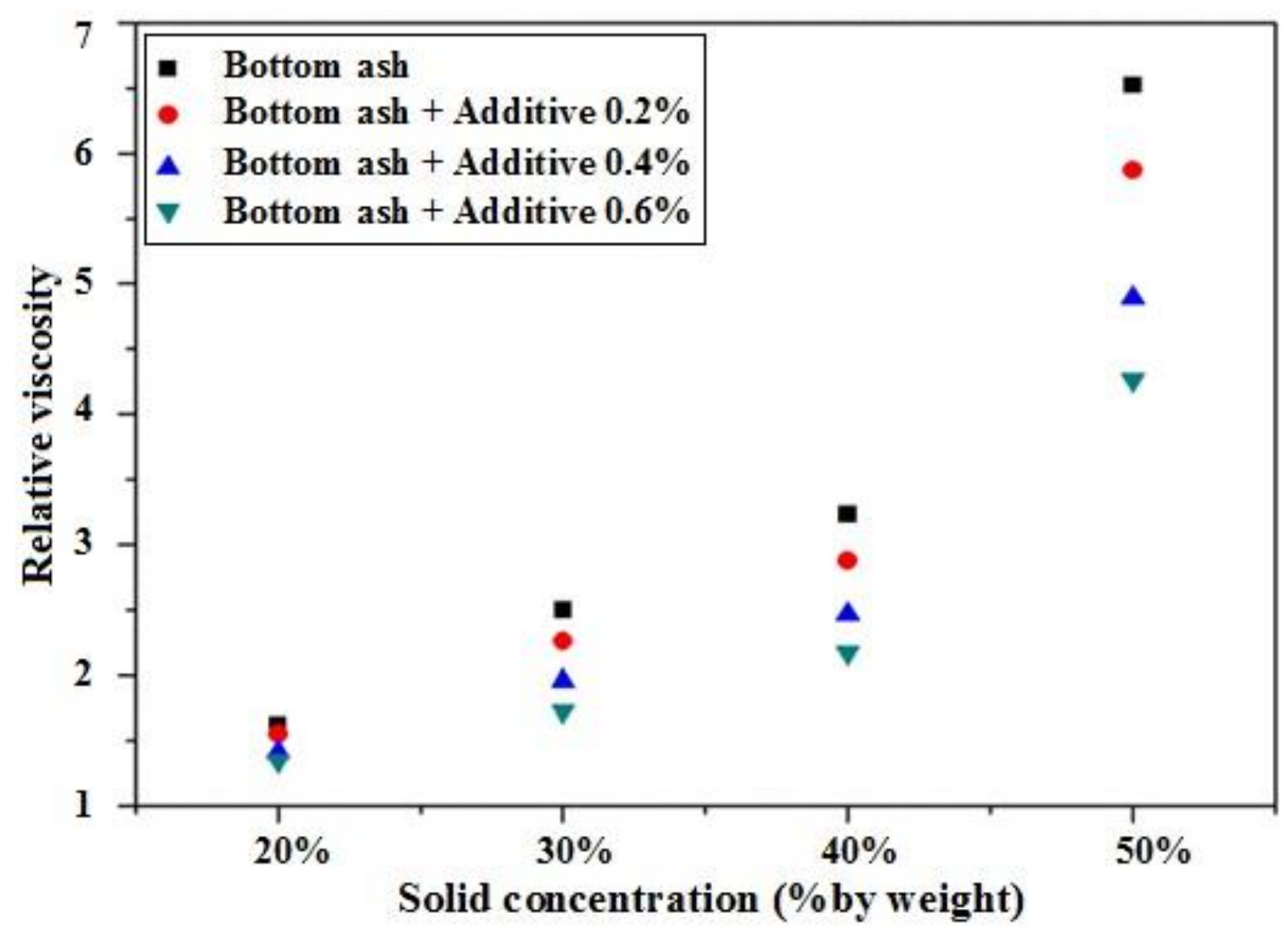

Fig. 5 Relative viscosity of bottom ash with and without additives

\section{Effect of additive on $\mathrm{pH}$ of bottom ash suspension}

In order to investigate the effect of additive on $\mathrm{pH}$ of bottom ash suspension, experimentation has been carried out with sodium sulphate as an additive in proportion of 0.2 , 0.4 and $0.6 \%$ (by weight). Digital electrode $\mathrm{pH}$ meter is used for measuring the $\mathrm{pH}$ value of bottom slurry suspension with solid concentration 20 to $50 \%$ (by weight). Experimental results indicate that $\mathrm{pH}$ of bottom ash suspension is increases with increase in concentration of additive. Variation in $\mathrm{pH}$ of bottom ash suspension with additive is shown in Fig. 6. For solid concentration of $50 \%$ (by weight) the $\mathrm{pH}$ of bottom ash suspension is observed as 7.4 and it increases as 7.48, 7.59 and 7.64 with addition of additive in $0.2,0.4$ and $0.6 \%$ (by weight) respectively. 


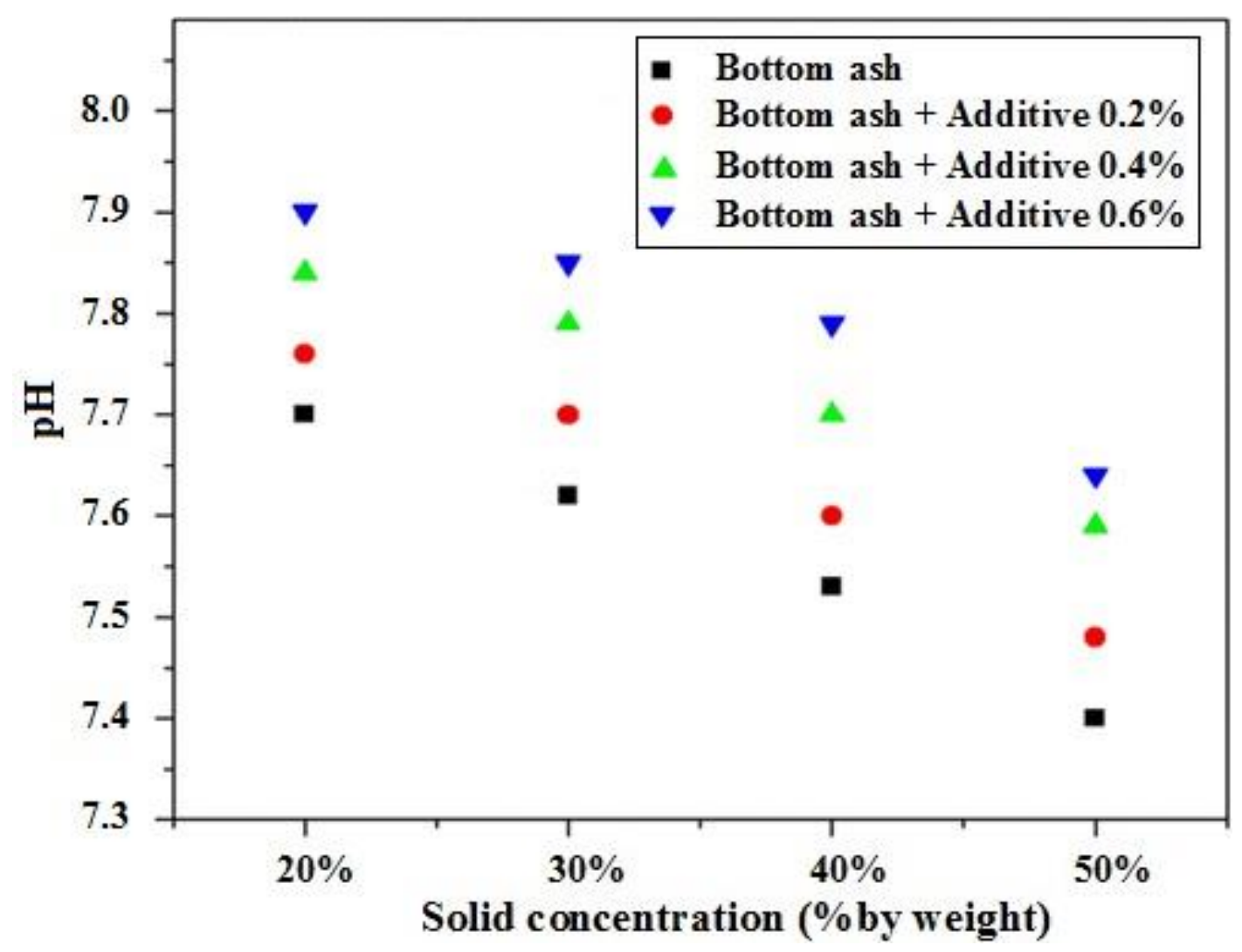

Fig. 6 Variation in $\mathrm{pH}$ of bottom ash suspension with additive

\section{$7 \quad$ Settling characteristics of bottom ash suspension with additive}

Static settled concentration of suspension is determined by gravitational settling method. Sodium sulfate is used as an additive in bottom ash slurry suspension in proportion of $0.2,0.4$ and $0.6 \%$ (by weight). The settling of bottom ash suspension with and without addition of additive for time variation is shown in Fig. 7. Initial solid concentration of bottom ash suspension was taken as $20 \%$ (by weight). The final static settling concentration of bottom ash suspension was found as $52.15 \%$. From the results, it is clear that settling concentration of bottom ash suspension decreases with increase in concentration of additive at a fixed value of time. It is observed that initially the settling concentration increases drastically with time and shows almost stability afterwards. Similar trend of settling behavior was observed in past study [18].

The static settling concentration of bottom ash suspension decreases with addition of additives at fixed value of time. The final static settling of bottom ash suspension is observed as $51.32,49.64$ and $49.21 \%$ with additive of sodium sulfate in $0.2,0.4$ and $0.6 \%$ (by weight) respectively. Maximum reduction in final settled concentration is observed with addition of sodium sulfate as an additive in proportion of $0.4 \%$ (by weight). This may be attributed addition of additive reduces the friction between adjacent layers of a suspension which causes decrease in settling of bottom ash suspension. This results in smooth flow of suspension [14, 18]. Researchers also drawn similar observations with fly and bottom ash slurry. Thus, the high concentration suspension can be disposed through pipeline system with a lesser principal investment cost or will be able to transport the bottom ash suspension economically with addition of small dosage of additive. 


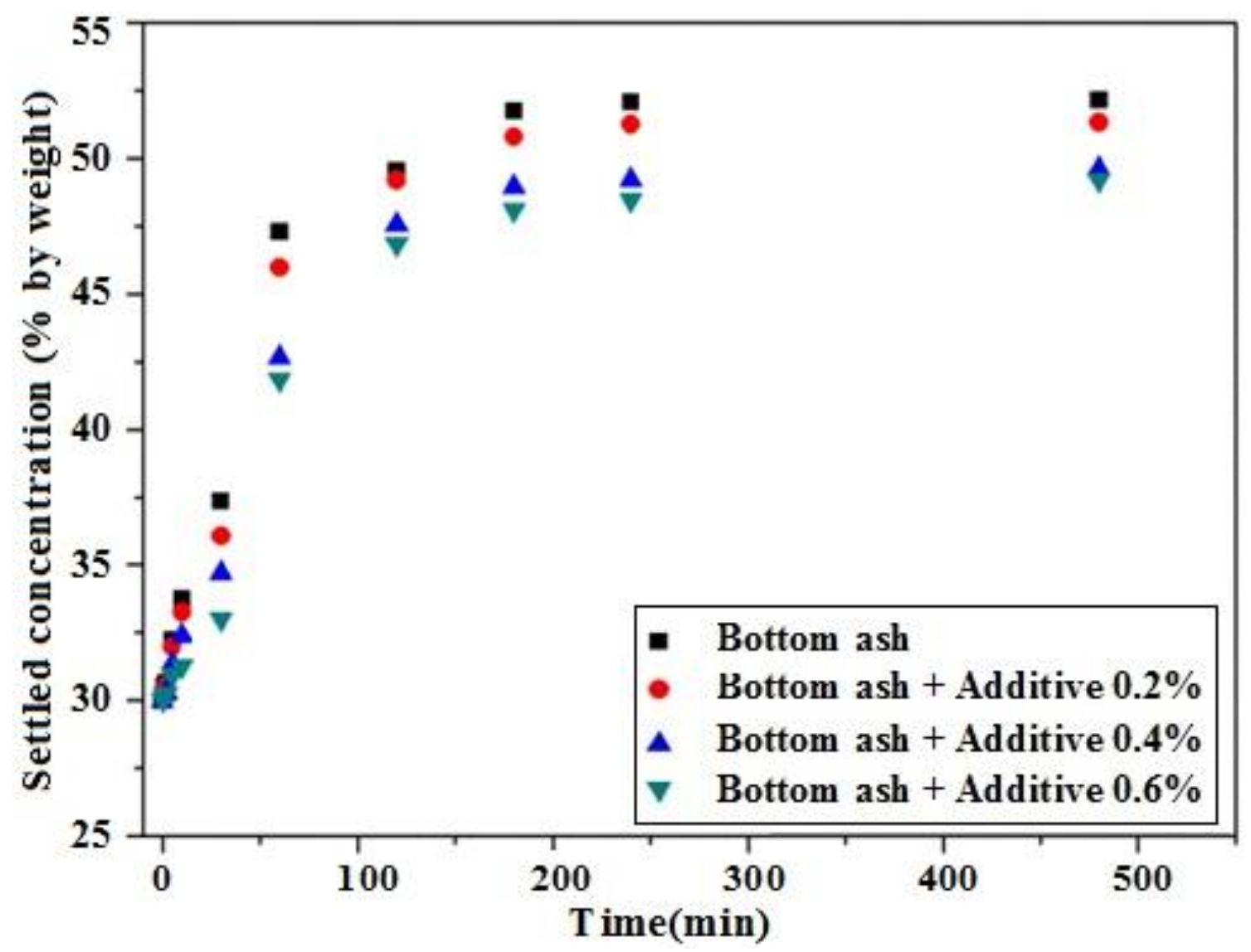

Fig. 7 Settling of bottom ash suspension with and without addition of additive

\section{CONCLUSION}

Based on present investigation for the rheological characteristics of bottom ash suspensions with and without addition of additives, it was concluded that addition of additives in bottom ash suspension improves the rheological characteristics of bottom ash suspension $[20,21]$. It was also concluded from the experimentation results that relative viscosities get reduced with addition of additive in bottom ash suspension. The reduction in relative viscosity and final settled concentration are highly noticeable with addition of sodium sulfate in proportion of $0.4 \%$ (by weight). Reduction in relative viscosity is highly pronounced at higher solid concentration [15]. The $\mathrm{pH}$ of bottom ash suspension increases with increase in concentration of additive whereas settled concentration decreases with addition of additive. Addition of additive can be beneficial for conveying bottom ash slurry suspension at higher concentration.

\section{REFERENCES}

[1] H. K. Naik, M. K. Mishra, U.M. Rao. Evaluation of flow characteristics of fly ash slurry at $40 \%$ solid concentration with and without additives, Denever, U.S.A. 2011.

[2] S. Kumar, B. K. Gandhi, S. K. Mohapatra. Leaching characteristics of bottom ash from thermal power plant. Energy Sources Part A: Recovery, Utilization and Environmental Effects 2016 (38), 686 - 694.

[3] V. K. Gahlot, V. Seshadri, R. C. Malhotra. Effect of density, size distribution, and concentration of solid on the characteristics of centrifugal pumps. Journal of Fluid Engineering 1992 (114) 386 - 389. 
[4] S. K. Mishra, P. K. Senapati, D. Panda. Rheological behavior of coal-water slurry. Energy Sources Part A: Recovery, Utilization and Environmental Effects 2002 (24), 59 $-167$.

[5] S. Veli, L. Kirli, B. Alyuz, E. Durmusoglu. Characterization of bottom ash, fly Ash, and filter cake produced from hazardous waste incineration. Polish Journal of Environmental Studies 2007 (17), 139 - 145.

[6] M. H. I. Ibrahim, N. Muhamad, A. B. Sulong. Rheological investigation of water atomized stainless steel powder for micro metal injection molding. International Journal of Mechanical and Materials Engineering 2009 (4), 1 - 8.

[7] S. R. Bbraganca, M. R. F. Goncalves, C. P. Bergmann, J. Rubio. Coal ash transportation as paste like highly loaded pulps in Brazil: characterization and main features. International Journal of Coal Preparation and Utilizations 2009 (29), 203 - 215.

[8] K. Sarnecki, A. Bartosik. Rheological analysis of an effect of different deflocculants on the fly-ash slurry. Journal of Physics 2014 (530), 1 - 8.

[9] M. Romagnoli, P. Sassatelli, M. Lassinantti, G. Tari. Rheological characterization of fly ash-based suspensions. Construction and Building Materials 2014 (65), 526 - 534.

[10] A. Parida, P. K Senapati, B. K. Mishra. Slurry pipelines for fly ash-a design method for energy efficient fly ash disposal by hydraulic conveying. Bulk Solids and Handling 2006 (26), $556-562$.

[11] D. Knezevic, B. Kolonja. The influence of ash concentration on change of flow and pressure in slurry transportation. International Journal of Mining and Mineral Engineering 2008 (1), $104-112$.

[12] S. Chandel, S. N. Singh, V. Seshadri. Deposition characteristics of coal ash slurries at higher concentrations. Advanced Powder Technology 2009 (20), 383 - 389.

[13] C. Hoschl, M. Okrouhlik. Solution of systems of nonlinear equations. Journal of Mechanical Engineering - Strojnícky časopis 2003 (54), No. 4, 197 - 227.

[14] R. Jančo. Solution of Thermo-Elastic-Plastic problems with consistent integration of constitutive equations. Journal of Mechanical Engineering - Strojnicky časopis, 2002 (53), No. 4, $197-214$.

[15] S. Mosa, H. M. S. Abdel, A. Taha, M. E. Anas. Effect of chemical additives on flow characteristics of coal slurries. Journal of Physicochemical Problems in Mineral Processing 2008 (42), 107 - 118.

[16] K. Trybalski, W. Kępys, D. Krawczykowski, A. Krawczykowska, D. Szponder. Physical properties of ash from co-combustion of coal and biomass. Polish Journal of Environmental Study 2014 (23), 1433 - 1436.

[17] S. Kumar, B. K. Gandhi, S. K. Mohapatra. Performance characteristics of centrifugal slurry pump with multi-sized particulate bottom and fly ash mixtures. Particulate Science and Technology 2014 (32), 466 - 476.

[18] B. K. Gandhi, S. N. Singh, V. Seshadri. Improvements in the Prediction of Performance of Centrifugal Slurry Pumps handling Slurries. Journal of Energy and Power Part A 2000 (214), 473 - 486.

[19] V. Seshadri, S. N. Singh, K. K. Jain, A. K. Verma. Effect of additive on head loss in the high concentration slurry disposal of fly ash. Journal of Institution of Engineers $\mathbf{2 0 0 8}$ (89), $3-10$. 
[20] S. Chandel, V. Seshadri, S. N. Singh. Effect of additive on pressure drop and rheological characteristics of fly ash slurry at high concentration. Particulate Science and Technology 2009 (27), 271 - 284.

[21] S. Kumar, S. K. Mohapatra, B. K. Gandhi. Effect of addition of fly ash and drag reducing on the rheological properties of bottom ash. International Journal of Mechanical and Materials Engineering 2013 (8), 1 - 8. 